\title{
Política de avaliação da aprendizagem no planejamento educacional do Município de Mossoró/Rio Grande do Norte
}

\section{Resumo}

\author{
Francisca Edilma Braga Soares Aureliano \\ Universidade do Estado do Rio Grande do Norte \\ Luciane Terra dos Santos Garcia \\ Maria Aparecida de Queiroz \\ Universidade Federal do Rio Grande do Norte
}

Este trabalho inscreve-se na pesquisa do Observatório de Educação (Capes) Avaliação do Plano de Ações Articuladas (PAR): um estudo em municípios do Rio Grande do Norte, Pará e Minas Gerais (2007 a 201 1). Focaliza a avaliação da aprendizagem nas edições do PAR em Mossoró (Rio Grande do Norte), município da amostra. Na perspectiva sócio-histórica, analisa a problemática da estratégia adotada pela nova gestão pública do Estado. Este, mediante contratos, induz os entes federados a compartilhar responsabilidades e a flexibilizar o controle das ações. A assistência individualizada e coletiva a estudantes, com aprendizagem defasada e necessidades educacionais especiais não reduz a exclusão decorrente dos padrões avaliativos.

Palavras-chave: Plano de ações articuladas. Avaliação da aprendizagem. Políticas educacionais.

\section{Policy of learning assessment in the educational planning in the Municipality of Mossoró/Rio Grande do Norte}

\section{Abstract}

This work is part of the research of the Observatory of Education (Capes) Evaluation of the Articulated Actions Plan (PAR): a study in the municipalities of Rio Grande do Norte, Pará and Minas Gerais (2007-2011). Focuses the learning assessment in editions of the PAR in Mossoró/RN, municipality sample. In the socio-historical perspective, it analyzes the problematic of the strategy adopted by the new public management in the state. This, by means of contracts, induces the federated entities to share responsibilities and to make more flexible the control of actions. Individualized and collective assistance to students with outdated learning and special educational needs does not reduce the exclusion resultant from evaluative standards.

Keywords: Articulated actions plan. Learning assessment. Educational policies. 


\section{Política de evaluación del aprendizaje en la planificación educativa del Municipio de Mossoró/Rio Grande do Norte}

\section{Resumen}

Este trabajo se inscribe en la investigación del Observatorio de Educación (Capes) Evaluación del Plano de Acciones Articuladas (PAR): un estudio en municipios de Rio Grande do Norte, Pará y Minas Gerais (2007 a 2011 ). Focaliza la evaluación del aprendizaje en las ediciones del PAR en Mossoró/RN, municipio de la muestra. En la perspectiva socio-histórica, analiza la problemática de la estrategia adoptada por la nueva gestión pública del Estado. Este, mediante contratos, induce a los entes federados a compartir responsabilidades y flexibilizar el control de las acciones. La asistencia individualizada y colectiva a estudiantes que tengan un aprendizaje desfasado y necesidades educacionales especiales no reduce la exclusión que se origina por los patrones evaluativos.

Palabras clave: Plano de acciones articuladas. Evaluación del aprendizaje. Políticas educacionales.

\section{Introdução}

artigo trata da formação inicial de professores tendo como foco as orientaçõEste trabalho que focaliza a dimensão da avaliação da aprendizagem inscreve-se na pesquisa do Observatório de Educação (Capes) - Avaliação do (PAR): um estudo em municípios do Rio Grande do Norte, Pará e Minas Gerais (2007 a 2011 1)'. A amostra contempla as capitais desses estados e mais quatro municípios, dentre eles, Mossoró/RN. O recorte da pesquisa analisa a problemática da avaliação na perspectiva sócio-histórica, privilegiada enquanto estratégia de política educacional do Estado brasileiro tendo, como referência, a nova gestão pública.

Esse arcabouço teórico privilegia contratos de gestão, possibilita que os entes federados compartilhem responsabilidades e flexibilizem o controle sobre as ações. A política nacional de educação que gerou o Plano de Ações Articuladas (PAR) foi instituída pelo Decreto n. 6.094, de 24 de abril de 2007 e constituiu um plano estratégico de caráter plurianual e multidimensional que inaugurou um novo regime de colaboração dos entes federados, sendo a União o principal financiador. Ademais, visa otimizar os indicadores de qualidade 
Francisca Edilma Braga Soares Aureliano | Luciane Terra dos Santos Garcia | Maria Aparecida de Queiroz

da educação básica brasileira revelados no Índice de Desenvolvimento da Educação Básica (ldeb). A primeira edição do PAR compreende o período de 2007 a 2010 e a segunda, o período de 2011 a 2014.

Nos estados e municípios, a formulação do PAR coube às Equipes Técnicas ${ }^{2}$ diretamente no Sistema Integrado de Monitoramento de Execução e Controle - SIMEC ${ }^{3}$, Módulo PAR/Plano de Metas, espaço virtual criado com essa finalidade. A metodologia de elaboração foi definida pelo Ministério de Educação e dela consta um diagnóstico da situação educacional consolidado no Guia de Orientação (BRASIL, 2007; 2011 ).

Sua estrutura é constituída por quatro dimensões: gestão educacional; formação de professores e dos profissionais de serviço e apoio escolar; práticas pedagógicas e avaliação; e infraestrutura física e recursos pedagógicos. As dimensões estruturam-se em indicadores, ações, subações e estratégias decorrentes das demandas. Consolidadas as definições, os entes federados assinam um termo de compromisso definindo as responsabilidades executivas de cada ente federativo, para consolidar o pacto federativo ${ }^{4}$.

Neste recorte da pesquisa, procedemos a uma revisão da literatura sobre políticas públicas, incluindo o PAR como estratégia de regulação da educação. Analisamos concepções de avaliação que fundamentam o plano; e procedemos a uma análise dos documentos que tratam da dimensão práticas pedagógicas e avaliação na edição do PAR de Mossoró/RN 2007-2010. Na análise, focalizamos as ações e subações de avaliação, contrapondo com a Lei $n^{\circ} 2.717$ de 27 de dezembro de 2010 que institui a política de responsabilidade educacional no município. Tomamos o PAR de 201 1-2014 como referência para verificar as mudanças transcorridas no primeiro PAR e as demandas subsequentes.

Discutindo sobre a análise documental, Lüdk e André (1986, p. 39) a consideram "[...] uma fonte poderosa de onde podem ser retiradas evidências que fundamentam afirmações e declarações do pesquisador e dos pesquisados. Representam, ainda, uma fonte 'natural' de informação." Esta pesquisa possibilitou a apropriação do ambiente empírico para que pudéssemos apreender e analisar a dinâmica de implementação dessa política. 


\section{Proposta de avaliação do PAR: política pública do Estado brasileiro}

As políticas públicas constituem-se em um campo de estudo multidisciplinar, polissêmico centrado na natureza e nos processos das ações públicas. Os estudos de Azevedo (2011), Azevedo (2003), Souza (2003) as definem como ações do Estado ou de organismos externos visando à resolução de problemas socioeconômicos que afetam um determinado segmento da população. Em face da realidade social e política, das mudanças no papel do Estado e da nova gestão pública, as políticas de educação se apresentam como meio para reduzir as desigualdades de oportunidades entre classes e grupos sociais marcantes no Brasil. Produzem-se programas constituídos por projetos que objetivam resolver problemas identificados.

termo política, tanto na língua portuguesa quanto nas demais, apresenta conotações distintas. Em inglês, são recorrentes os termos politics e policy. Politics é compreendida como "[...] atividade humana, está associada à obtenção e à manutenção dos recursos necessários para o exercício do poder sobre o homem" (SECCHI, 2010, p. 1). Rua (1998) corrobora esse conceito tomando-o como um conjunto de procedimentos formais e informais

102 que expressam relações de poder e se destinam à pacificação de conflitos na disputa pelos bens públicos.

O conceito de políticas se materializa na policy que implica decisões e ações (SECCHI, 2010), ou seja, na dimensão material dos conteúdos de programas, problemas técnicos e decisões políticas. A esse significado, associa-se a política pública (public policy), a qual se integram as políticas educacionais. Azevedo (2003) considera política pública um programa em ação que visa à mudança de situações problemáticas que requerem soluções quase sempre configuradas alvo de ações em que predomina a atuação do Estado.

Configuram, às vezes, ações governamentais específicas de regulação econômica, política e social, formuladas, implementadas e avaliadas por um governo central cuja execução se estende aos demais entes federados com decisões abrangentes. Não se limitam, portanto, a leis ou a regras; são intencionais, têm objetivos e metas a serem alcançados, a curto, médio ou longo prazo. Conforme Azevedo (2003, p. 38), "[...] é tudo o que um governo faz e deixa de fazer, com todos os impactos de suas ações e de suas omissões."

Em face dessas definições de política pública, entendemos que é um campo de estudo multidisciplinar centrado em explicações sobre a natureza e 
Francisca Edilma Braga Soares Aureliano | Luciane Terra dos Santos Garcia | Maria Aparecida de Queiroz

os processos das ações públicas. Suas contribuições conceituais emanam das Ciências Sociais, pois repercutem na vida social e econômica, implicando compreender as relações entre a sociedade, o Estado, a política e a economia. Essa discussão é enriquecida com a compreensão de Souza (2003) de que as políticas públicas, ao mesmo tempo que enriquecem os processos democráticos, favorecem os "[...] propósitos e plataformas eleitorais em programas e ações que produzirão resultados ou mudanças no mundo real" (SOUZA, 2003, p. 12).

Para melhor compreendê-las, vislumbramos sua classificação em programas, planos e projetos. Segundo Cohen e Franco (1999), os programas englobam projetos distintos, correspondentes a um conjunto de propostas com os mesmos objetivos para atender a problemas específicos sinalizados em um plano. Este, por sua vez, consiste de um documento produzido por um governo, com objetivos, diretrizes (políticas), estratégias e meios com uma intencionalidade. Os projetos são componentes de um programa, também desenvolvidos para solucionar problemas que afetam um determinado segmento da população. Projetos e programas operacionalizam, pois, as políticas públicas.

Essas políticas, em educação, se definem enquanto um conjunto de programas, constituídos de projetos para resolver problemas desse campo. Alguns, identificados na educação brasileira, geram demandas focalizadas em determinados setores, respondendo a mecanismos de gestão baseados no aporte legal e normativo. É nesse esboço institucional que configura o Plano de Desenvolvimento da Educação (PDE), apresentando metas e estratégias para a educação básica a serem operacionalizadas nos Estados e municípios. Nestes a política governamental é organizada e operacionalizada mediante o Plano de Ações Articuladas (PAR).

Caracterizado como um programa de governo, inscreve-se no Plano Plurianual (PPA) 2008-2011 - Lei n 1 1.653, de 7 de abril de 2008 - correspondente ao segundo mandato presidencial de Luiz Inácio Lula da Silva. Um de seus eixos é a educação de qualidade, considerando "A competitividade econômica, a equidade social e o desempenho do cidadão são simultaneamente impactados pela educação" (BRASIL, 2008, p. 16). Compreendendo a qualidade como objetivo estratégico para o desenvolvimento da Nação, o Governo Federal formulou e executa o Plano de Desenvolvimento da Educação (PDE). 
Enquanto plano executivo, desdobra-se em programas específicos organizados em quatro eixos: educação básica, educação superior, educação profissional e alfabetização. Reúne ações articuladas com abordagem no sistema educativo nacional e nos diferentes níveis de ensino. Nesse sentido, alerta a sociedade sobre a importância da participação de pais, estudantes, professores e gestores e os compromete em iniciativas que vislumbram o acesso, a permanência e o sucesso dos estudantes no processo de escolarização.

Acena com a parceria público-privado que se consolida no movimento Compromisso todos pela Educação integrado por empresários brasileiros. A partir dele, foi produzido o Plano de Metas Compromisso todos pela Educação ao qual aderiram os governos subnacionais, comprometendo-se a cumprir suas vinte e oito diretrizes. Imprimem-se, pois, metas e ações que representam a conjugação de esforços dos entes federados.

Ampliaram-se, dessa forma, os compromissos da União com os Estados, Municípios e Distrito Federal, aplicando-se os princípios federativos para fortalecer o regime de colaboração na política educacional. Assim, a tendência seria corrigir distorções, inclusive, as desigualdades nas relações políticas intra e inter-regional. Ao assinarem o Plano de Metas, os governos 104 subnacionais aderiram à política que o consolidou, ou seja, o Plano de Ações Articuladas (PAR) que deveria ser elaborado e implementado em sua primeira edição 2007-201 1 .

Naquele momento, o Brasil ingressava, portanto, em uma fase de crescimento econômico, implementando políticas, principalmente, de redução das desigualdades, a exemplo do Programa Fome Zero, ganhando, assim, visibilidade no cenário internacional (ANDERSON, 201 1). Em educação, um conjunto de medidas decorrentes da União impulsionou a dinâmica do planejamento para atender, inclusive, às demandas do capital. As políticas eram orientadas por princípios neoliberais e neoconservadores.

Nesse contexto, a educação adquiriu centralidade por representar a base para o desenvolvimento dos processos científicos e tecnológicos que funcionam como motores das forças produtivas. Regulada pelo mercado e pautada nos pressupostos da nova gestão pública, adotou as teorias e as técnicas gerenciais próprias do campo da administração de empresas. $\bigcirc$ modelo de administração gerencial foi implantado na esfera pública na década de 1980 pelos governos conservadores da Grã-Bretanha e Estados Unidos, passando, 
Francisca Edilma Braga Soares Aureliano | Luciane Terra dos Santos Garcia | Maria Aparecida de Queiroz

a partir de então, a influenciar a reforma administrativa dos Estados-nação, demandando contínuas adequações decorrentes das críticas que tem suscitado (ABRÚCIO, 2005).

Essa estrutura teórica da nova administração pública embasou a reforma administrativa do Estado brasileiro e, consequentemente, dos serviços educacionais, desde a década de 1990, objetivando flexibilizá-los e agilizá-los. Seguindo essa lógica, a União transferiu para os demais entes federados a responsabilidade pela implementação das políticas educacionais formuladas nessa instância, regulando-as a distância sob diversas formas de acompanhamento, controle e avaliação. A execução das metas é compartilhada, de forma colaborativa, de modo que os entes federados (instituições públicas e privadas bem como grupos sociais/atuem com relativa autonomia.

O Plano de Ações Articuladas (2007-20 1 1/20 1 1-2014) obedece aos princípios gerenciais, na forma de contratualização que, conforme Formosinho, Fernandes e Machado (2010), envolve entidades responsáveis pela educação pública - universidades, escolas e municípios - estimuladas a alcançar objetivos negociados. $\bigcirc$ contrato prevê um cronograma de execuções das ações e, não raro, efetiva-se a partir de formas de financiamento compartilhadas (FORMOSINHO; FERNANDES; MACHADO, 2010). Em relação ao PAR, o contrato é formalizado entre o MEC e as Secretarias Municipais e Estaduais de Educação mediante o planejamento estratégico que organiza, acompanha e avalia a execução das metas previstas. Esse processo possibilita melhor utilização e transparência na aplicação dos recursos possibilitando "[...] responsabilização, aprendizado, ação pedagógica, reafirmação da política pública, troca de informações, fornecimento de orientações e formação permanente das equipes [...]" (CAMINI, 2010, p. 544).

Dos serviços educacionais nos sistemas e redes de ensino, é requerido o melhor desempenho orientado pelos pressupostos teóricos das competências e das habilidades relacionadas ao trabalho, ao controle sobre os conteúdos curriculares e à avaliação. O objetivo principal dessa política educacional consiste em mostrar bons resultados, fortalecendo os laços entre escolarização, trabalho, produtividade, serviços e mercado para melhorar a economia nacional (AZEVEDO, 2003). Adequando-se às disposições mercadológicas e implementando estratégias de acumulação do capital, o Estado atua na implementação de políticas públicas, de modo particular em educação, tendo, por base, a parceria público-privada. 
Política de avaliação da aprendizagem no planejamento educacional do Município de Mossoró/Rio Grande do Norte

Analisando a regulação estatal, Barroso (2005) considera-a mais flexível na definição dos processos, no entantose pauta por rigorosa análise da eficiência e da eficácia, enfatizando os resultados. A avaliação de desempenho assumiu centralidade como instrumento de controle da qualidade da educação. Para isso, criaram-se sistemas nacionais de avaliação ${ }^{5}$ e os índices ${ }^{6}$ que medem o rendimento da aprendizagem.

A divulgação oficial dos índices revela transparência dos dados que suscitam críticas por parte da sociedade, principalmente, por meio das mídias. Ademais, responsabilizam a escola, os profissionais da educação, os pais dos estudantes por acompanhar a qualidade do ensino, criar e implementar ações pedagógicas para melhorá-la. Formaliza-se, portanto, um ranking entre os sistemas, redes de ensino e escolas, estimulando a competição e influenciando, principalmente, as decisões orçamentárias. Considerando o PAR, objeto dessa discussão, esse arcabouço institucional se reflete na formulação do planejamento das ações dos municípios.

Aqueles que apresentam os menores índices e maiores carências em determinados aspectos, são priorizados nas ações de educação visando reduzir as desigualdades, ou seja, os problemas acumulados historicamente (BRASIL, 106 2008). Decorrentes da desresponsalização do poder público, os problemas do campo da educação são denunciados na carência de vagas, evasão, reprovação, distorção idade/série/ano de escolarização. A realidade é agravada pela precariedade das condições físicas, materiais, pedagógicas, formação de pessoal e funcionamento das redes de ensino que não são recomendadas aos processos de ensino e de aprendizagem. Conceber, assim, a avaliação contraria o entendimento de que como prática social e política contribui para caracterizar, compreender, divulgar e indicar soluções a problemas sociais, em particular, inerentes à educação.

Essa compreensão contrapõe-se ao projeto de educação que se estende por mais de duas décadas, atribuindo um papel crucial à avaliação, porém reduzindo sua potencialidade conceitual. Associada, diretamente, ao crescimento econômico, a avaliação impõe-se como método para dimensionar o custo-benefício, em particular das ações políticas, em nível macro ou micro, a exemplo do processo ensino-aprendizagem. Insistimos que a inclusão de ações de avaliação da aprendizagem no PAR dos municípios brasileiros impõe o controle sobre os índices de aprendizagem dos estudantes como a principal referência nas definições orçamentárias. 
A escolha de critérios para pontuar os indicadores do PAR representa as demandas da educação dos municípios que resultam do diagnóstico realizado no período de sua formulação. Assim, por meio da avaliação, todos os municípios passam a controlar os resultados da qualidade de ensino para garantir o financiamento. Em decorrência, no PAR, são geradas ações de avaliação, inclusive, de aprendizagem dos alunos. Dentre as ações, inclui-se a formação das equipes das escolas para trabalhar com estratégias de avaliação e reformulação do projeto político-pedagógico. É requerido ainda atenção especial aos alunos que apresentam transtornos de aprendizagem; assistência coletiva e individualizada para aqueles que têm dificuldades de aprendizagem; e implementação de política de correção de fluxo.

\section{A avaliação da aprendizagem no Plano de Ações Articuladas}

Na educação, a avaliação refere-se a um conjunto de ações desenvolvidas, sistematicamente, para analisar o processo de ensino-aprendizagem, as ações pedagógicas e organizacionais assim como a implementação de políticas e programas. O desenvolvimento da prática avaliativa depende do referencial teórico e metodológico que orienta as ações na consecução de objetivos. Apesar de não ter finalidade em si mesma, a avaliação reforça valores que colaboram para manter ou transformar as relações sociais. Chueiri (2008) ressalta o papel do avaliador como aquele que atribui sentido e significado ao processo avaliativo e, por meio deste, produz conhecimento e representações, tomando como base suas próprias "[...] concepções, vivências e conhecimento" (CHUEIRI, 2008, p. 52).

Assim, a avaliação educacional se transforma, historicamente, conforme as mudanças sociais, sob a orientação de determinada concepção de Ciência, Filosofia e Pedagogia. Conforme Dias Sobrinho (2013), somente no início do século XX, tornou-se uma prática políitca e pedagógica orientada pelo paradigma positivista. Até meados da década de 1960, restringiu-se à aprendizagem, tendo, como foco, o aluno, seguindo-se de uma vasta produção específica voltada para "[...] currículo, programas, cursos, projetos, materiais didáticos, políticas públicas e, mais recentemente, avaliação de instituições" (SAUL, 2009, p. 95). 
Em contraposição a esse paradigma, novos modelos científicos e pedagógicos influenciaram as práticas avaliativas. Conforme Dias Sobrinho (2013, p. 43), sob a orientação da Fenomenologia, "[...] a avaliação tornou-se multidisciplinar, incorporando também as contribuições da sociologia, da economia e da antropologia, além de, obviamente da educação e da psicologia." Desenvolveu-se, então, um conjunto de paradigmas de avaliação considerados progressistas, emancipatórias, formativos, dialéticos, de forma que, apesar de não se tornarem hegemônico, constituem-se em resistência ao instituído.

Nos anos setenta ${ }^{7}$, esse novo paradigma não se tornou hegemônico, pois a política de formação de profissionais da educação induziu cursos de pós-graduação no exterior, em particular, nos Estados Unidos da América. $\bigcirc$ intercâmbio possibilitava a presença de técnicos norte-americanos realizando treinamento de professores brasileiros (SAUL, 2009), com ênfase no pensamento positivista. Essa concepção de avaliação escolar estava, pois, associada ao enfoque eminentemente técnico de julgamento de valor, medição de aprendizagem, classificação de desempenho com base em critérios definidos como desejáveis (DIAS SOBRINHO, 2013).

Essa concepção privilegia a análise de resultados, a eficácia e a eficiência dos serviços oferecidos em detrimento dos fatores que interferem no processo educativo. Supostamente pautada em critérios de neutralidade de valores, despreza a diversidade organizacional e pessoal, adotando indicadores quantitativos e a lógica meritocrática que a torna instrumento de controle dos resultados para perpetuar as relações de poder.

Com esses objetivos, no interior da escola, a avaliação é realizada por profissionais para verificar a aprendizagem dos conteúdos curriculares dos estudantes, utilizando instrumentos e técnicas avaliativas ao final de determinados períodos. Conforme Luckesi (2003), esse tipo de avaliação se ancora na Pedagogia do Exame, na qual os estudantes, pais, professores, escolas e sistemas de ensino têm, como foco principal, a aprovação ou a reprovação do educando. Segundo essa lógica, os alunos estão interessados, em primeira instância, em conhecer as normas e os meios de manipulação das notas que propiciarão, ou não, sua aprovação para o ano de escolaridade seguinte. Os professores utilizam as provas e/ou testes como instrumento de ameaça e motivação para a aprendizagem. Os pais vão à escola para receber boletins e conversar com os professores sobre o aproveitamento do filho. 
Francisca Edilma Braga Soares Aureliano | Luciane Terra dos Santos Garcia | Maria Aparecida de Queiroz

estabelecimento de ensino constrói quadros estatísticos com os resultados e os sistemas de ensino, enfim, controlam os resultados gerais (LUCKESI, 2003).

As avaliações externas às escolas desenvolvidas em âmbito nacional, na atualidade, reproduzem essa lógica meritocrática e a busca pela eficiência e eficácia dos resultados pelos quais os sujeitos são responsabilizados. Os sistemas de avaliação nacionais desconsideram as diferenças individuais e as desigualdades sociais e econômicas, fomentando a competitividade como meio para impulsionar a melhoria da qualidade educacional.

Afastando-se dessa perspectiva, Romão (2011) considera que as teorias de avaliação progressistas têm as seguintes características: a valorização da autoavaliação; ênfase em dados qualitativos para subsidiar diagnósticos sobre a realidade; processo realizado de forma permanente; consideração dos códigos locais e sociais bem como dos ritmos pessoais. A realização de um diagnóstico envolvendo os sujeitos das organizações educativas possibilita dimensionar os problemas, monitorar, controlar e avaliar os avanços e as dificuldades com vistas à redefinição de objetivos, metas e ações, baseadas em dados de naturezas diversas. Dados estatísticos de acesso, permanência, aprovação, reprovação, evasão, índices de aprendizagem, origem socioeconômica, cultura organizacional, condições de execução do trabalho educativo, referendam o conjunto da realidade da educação e suas particularidades.

Nessa perspectiva, a avaliação é diagnóstica, contínua, formativa, além de somativa, por ser empregada em diferentes momentos do processo de ensino-aprendizagem (no início, durante e no final) com diferentes finalidades. No início do curso ou etapa do ensino, é realizada com o objetivo de coletar dados para o planejamento das ações. Dessa forma, é possível definir as estratégias didáticas mais adequadas aos sujeitos e à realidade escolar.

$\bigcirc$ processo avaliativo deve ocorrer de forma contínua subsidiando reflexões e decisões dos profissionais da educação visando à melhoria do trabalho docente. No entendimento de Arredondo e Diago (2009), a avaliação processual é formativa, porque permite obter informações acerca dos estudantes no percurso da aprendizagem, pois os dados obtidos possibilitam "[...] reorientar, regular, modificar ou reforçar o processo educacional de cada um" (ARREDONDO; DIAGO, 2009, p. 61). Ademais, para os autores (2009), a função reguladora do ensino e da aprendizagem possibilita prever as 
possibilidades de atuação e/ou os rendimentos dos educandos; retroalimentar o processo e controlar a obtenção de informações.

Nesse processo, a análise dos erros e dos acertos dos educandos constitui-se em fonte de informações, visto que demonstra seus saberes, hipóteses de construção de conhecimentos, percursos de aprendizagem, imprescindíveis ao trabalho docente. Esteban (2002) defende que distante de o erro demonstrar ausência de conhecimento ou incapacidade do educando, denota a complexidade do processo de ensino-aprendizagem. Quando o professor indaga acerca das respostas equivocadas dos estudantes pode identificar seus conhecimentos e as relações estabelecidas entre eles. Torna-se importante trabalhar as dúvidas e construir situações em que o educando teste hipóteses sobre a construção do conhecimento (ESTEBAN, 2002).

Ao final do processo de ensino-aprendizagem, a avaliação tem por finalidade analisar o alcance dos objetivos traçados inicialmente. A perspectiva somativa "[...] dá uma dimensão do significado e da relevância do trabalho realizado [...]" (AZZI, 2001 , p. 19). É tradicional, na avaliação positivista, que essa função represente o aproveitamento da aprendizagem dos estudantes por meio de conceitos ou notas, com base nos quais se define a aprovação ou

110 reprovação, comparando-se e classificando-se o desempenho dos estudantes. A concepção progressista não exclui a função somativa da avaliação na culminância do processo, mantendo, assim, a inclusão dos estudantes, pois embasa o planejamento das atividades pedagógicas.

Assim, as diferentes funções da avaliação são importantes para a escolarização, sendo ressaltadas conforme a concepção de educação que embasa a atuação das pessoas e instituições quanto às políticas educacionais. A partir desses pressupostos teóricos, passamos a analisar a ações e subações do PAR do Município de Mossoró referentes à avaliação da aprendizagem.

\section{Análise das proposições de avaliação no PAR em Mossoró/RN}

$\bigcirc$ discurso governamental sobre avaliação e monitoramento das políticas públicas prioriza a melhoria dos serviços, como direito à educação com qualidade. Constitui-se em um desafio a ser enfrentado, pois os governos consideram que não existem recursos financeiros suficientes para atender às demandas desse campo. Nesse argumento, identificam-se contradições, visto 
Francisca Edilma Braga Soares Aureliano | Luciane Terra dos Santos Garcia | Maria Aparecida de Queiroz

que esses recursos são alocados, em tempo hábil, para os setores rentáveis ao capital, a exemplo de grandes obras que interessam às empreiteiras.

Os serviços sociais, no entanto, tropeçam na alocação de recursos financeiros principalmente porque falta vontade política por parte dos dirigentes para resolver problemas de educação, saúde, habitação, saneamento básico, transporte público, esporte e lazer. Inversamente a essa lógica, para tornar a gestão pública eficiente, o planejamento e a avaliação deveriam ser compatíveis com os problemas e as ações públicas seriam eficazes alcançando resultados positivos. Esses atributos só serão concretizados se as demandas decorrentes desse campo integrarem a agenda política em termos de orçamento, liberação de verbas em tempo hábil, acompanhada e avaliada sistematicamente.

Ademais, a implementação de políticas bem-sucedidas estão condicionadas à lisura na gestão, principalmente na aplicação dos recursos. Isenta, portanto, de estratégias de corrupção e de clientelismo, sob um rigoroso controle de instâncias de fiscalização, dentre outros, os tribunais de conta, o Ministério Público e os conselhos.

As definições relativas às recentes políticas educacionais brasileiras são regulamentadas pela Constituição Federal de 1988, Lei de Diretrizes e Bases da Educação Nacional, Lei n 9.394, de 20 de dezembro de 1996 (BRASIL, 1996); Lei n 9.424, de 24 de dezembro de 1996 (BRASIL, 1996a); Lei n ${ }^{\circ}$ 10.172, de 9 de janeiro de 2001, (BRASIL, 2001) - Plano Nacional de Educação (PNE 2001-2010) - e a Lei n 13.005, de 25 de junho de 2014 (BRASIL, 2014) - atual PNE (201 1-2020). Implicam princípios e conceitos que orientam as práticas políticas, em especial, de natureza democrática que contemplam a qualidade de vida das pessoas em circunstâncias que ultrapassam tempos e lugares da escolarização propriamente dita.

Contrapondo a concepção de qualidade social, a administração gerencial atribui, ao termo, características e procedimentos que são aplicados para avaliar o grau de satisfação do cliente em termos de bens e serviços. Conforme Casassus (1999), essa estratégia se vincula diretamente à teoria gerencial tendo o mercado como regulador da qualidade educacional. Por outro lado, o resultado de qualidade em nível escolar se projeta no conjunto do sistema. Para Gadotti (2013), essa perspectiva de qualidade é excludente porque se estende a minorias, sendo necessário, no entanto, que as políticas estejam embasadas em uma concepção de qualidade de natureza includente. 
Nesse sentido, a qualidade social implica um tipo de educação para reduzir as desigualdades de oportunidades que são reforçadas por "[...] um contingente enorme de municípios pequenos, com baixa capacidade de sobreviver apenas com recursos próprios" (ABRUClO, 2005, p. 48). A correção de distorções é, pois, a proposta do Plano de Desenvolvimento da Educação PDE (BRASIL, 2007) que se concretiza por meio do PAR em seus desdobramentos nos estados e nos municípios.

A análise documental do PAR (2007) de Mossoró/RN evidenciou que a Secretaria Municipal de Educação já desenvolvia ações de avaliação e de correção de fluxo escolar, para superar os problemas de aprendizagem e a distorção da idade-série. Em 201 1, ampliou a atenção atribuída à avaliação da aprendizagem, instituindo, supostamente, a perspectiva processual.

Assim, as ações de avaliação no PAR estão somente na área 2 que correspondem à aprendizagem dos alunos que apresentam dificuldades de aprendizagem, enquanto parte da dimensão práticas pedagógicas e avaliação. É constituída por três indicadores: formas de avaliação da aprendizagem dos alunos; utilização do tempo para assistência individual/coletiva aos alunos que apresentam dificuldade de aprendizagem e necessidades educativas 112 especiais; e, política específica de correção de fluxo.

Esses indicadores estavam no diagnóstico do PAR conforme os critérios do guia de orientação (BRASIL 2007a; 201 1). A pontuação variava entre 1 e 4, respectivamente situação crítica, insuficiente, apresenta mais aspectos positivos do que negativos esituação positiva. Na primeira edição do PAR (2007-201 1), as situações avaliadas com 3 e 4 não geravam ação para atender às demandas do indicador em evidência. Enquanto na edição de 2011 a 2014, todos os critérios geravam ações e subações.

$\bigcirc$ indicador "Formas de avaliação da aprendizagem dos alunos" (MOSSORÓ, 2007, p. 21), nesse município, recebeu a pontuação 3, porque atendia, plenamente, à realidade do município, não gerando ações nem subações. Em 2011 , mesmo com a pontuação 4 (positiva), gerou a ação de "Manter as equipes pedagógicas e os professores atualizados sobre estratégias para avaliação dos alunos e realização de práticas interdisciplinares, considerando as diretrizes estabelecidas pela Secretaria Municipal de Educação e os projetos pedagógicos das escolas" (MOSSORÓ, 201 1, p. 129). As subações subsequentes foram direcionadas para a continuidade de cursos 
Francisca Edilma Braga Soares Aureliano | Luciane Terra dos Santos Garcia | Maria Aparecida de Queiroz

de aperfeiçoamento dos profissionais vinculados à Secretaria capacitando-os para produzir práticas avaliativas priorizando as necessidades de aprendizagem dos estudantes.

foco da dinâmica centrava-se no fortalecimento das práticas pedagógicas e na avaliação contínua do processo de ensino e aprendizagem. A proposta consiste de qualificação da equipe pedagógica da secretaria municipal de educação e dos demais componentes da comunidade escolar. Contempla a discussão de critérios de avaliação dos estudantes, conforme as diretrizes emanadas do órgão municipal e dos projetos pedagógicos (PP) das escolas. A outra subação direcionava-se para a discussão de metodologias de avaliação dos alunos, assim como a práticas interdisciplinares. A partir desse momento, é sugerida a produção de um documento orientador das práticas pedagógicas, bem como a avaliação nas escolas da rede de ensino. Ambas subações se inscreviam na competência municipal ${ }^{8}$.

Constatamos, portanto, analisando o PAR de Mossoró (2007), que o município desenvolvia antes deste, programas de consolidação de práticas avaliativas nas escolas da rede, orientados pela Lei n².717, de 27 de dezembro de $2010^{9}$. Ademais, tinha, como referência, os projetos político-pedagógicos das escolas. Objetivava, assim, promover a melhoria da qualidade do ensino por meio do planejamento das ações, da definição de metas educacionais, do investimento crescente e sistemático de recursos e da avaliação de desempenho. O dispositivo legal, no art. 10, leva à compreensão de que

Os indicadores e os resultados de cada uma das unidades educacionais deverão ser superiores, ao ano anterior. Parágrafo Único - Os indicadores e resultados que se [referem] os caputs serão apurados por ocasião da avaliação do Prêmio Escola de Qualidade, já instituído pelo Município (MOSSORÓ, 2010, p. 5).

Pelo que observamos na legislação, a avaliação, na rede de ensino, privilegia os resultados, induz a premiações e honrarias que se estendem aos segmentos da escola e a membros da sociedade, tendo a meritocracia como princípio. Todos os segmentos da comunidade escolar são avaliados e os melhores são contemplados com benesses. Conforme o art. 11 parágrafo $1^{\circ}$ ao $7^{\circ}$, algumas categorias são premiadas em dinheiro, sendo os profissionais em valores equivalentes à remuneração do servidor e os alunos com depósito em caderneta de poupança (MOSSORÓ, 2010). 
Políitica de avaliação da aprendizagem no planejamento educacional do Município de Mossoró/Rio Grande do Norte

A conduta administrativa demonstra a influência do arcabouço gerencial que, por meio da avaliação de desempenho, estimula a competição entre os sujeitos e as instituições para fomentar a melhoria da qualidade dos serviços públicos (ABRÚCIO, 2005). Torna a avaliação um mecanismo flexível e eficaz de controle sobre as instituições escolares responsabilizando os sujeitos pelos resultados obtidos.

indicador "Utilização do tempo para assistência individual/ coletiva aos alunos que apresentam dificuldade de aprendizagem" recebeu, em 2007, a pontuação correspondente à situação crítica. Suscitou a demanda de elaboração de um projeto para assistir, individualmente e/ou de forma coletiva, aos estudantes, no sistema municipal, com essas dificuldades. Para atendê-las, foi necessário gerar a ação de incluir, no Projeto Pedagógico das escolas, o componente de assistência individual e coletiva e atendimento educacional especializado àqueles com necessidades educativas especiais.

As subações dessa ação estão relacionadas com a assistência do município para propiciar condições às escolas e aos professores que atendem aos estudantes de forma individual ou em grupo. Coube, ainda, qualificar os professores por meio do Programa de Formação Continuada do Ministério 114 da Educação (MEC); proceder à divulgação do tempo de apoio aos alunos com dificuldades em aprender; promover o acompanhamento desse apoio. Ademais, sob a responsabilidade do MEC, o município passou a oferecer pelo "Programa Educação Inclusiva: direito à Diversidade" a formação dos professores que trabalham com alunos com necessidades especiais.

Torna-se premente para o sistema municipal preparar os professores que atendem aos estudantes com dificuldades de aprendizagem e necessidades educacionais especiais. Além dessa assistência ser um direito subjetivo, quando as escolas aderem a projetos específicos, visam, também, ao alcance das metas estabelecidas quanto aos resultados gerais que podem ser comprometidos. Freitas (2012) alerta para o fato de que a realidade suscita exclusão dos educandos ou leva a sua segregação criando-se o estigma de instituições com qualidade inferior ou superior. Ademais, o escalonamento na rede de ensino compromete os investimentos em determinadas escolas que são privilegiadas com recursos financeiros em detrimento de outras.

$\bigcirc$ mesmo indicador no PAR de Mossoró em 2011 foi pontuado, satisfatoriamente, mas gerou ação diante da necessidade de contemplar o 
Francisca Edilma Braga Soares Aureliano | Luciane Terra dos Santos Garcia | Maria Aparecida de Queiroz

indicador com o "[...] fortalecimento da assistência individual/coletiva, aos alunos que apresentam dificuldade na aprendizagem" (MOSSORÓ, 2011, p. 130). A ação desencadeada, nessa demanda, foi mais consistente, pois, enquanto no PAR anterior, voltava-se para a qualificação das equipes, neste a pretensão era garantir durante todo o ano letivo, as condições necessárias para atendimento dos alunos com dificuldades de aprendizagem.

Diferentemente do PAR de 2007, que trazia subações nesse indicador, promovidas com apoio técnico do MEC, em 201 1, todas são de responsabilidade do município. Das três subações de competência desse ente no antigo PAR, fica excluída do atual, a de promover o acompanhamento do apoio ao atendimento individual e coletivo aos alunos com dificuldades de aprendizagem. Essa exclusão demonstra a descontinuidade de um dos principais aspectos da avaliação que é construir as condições para o acompanhamento dos avanços ou estagnações das aprendizagens dos alunos, o que pode comprometer as demais subações desse indicador.

É provável que o fato decorra da lógica gerencial predominante nas políticas educacionais brasileiras, e, em particular, no município de Mossoró. Conforme essa lógica, os entes federados e as instituições de ensino são corresponsáveis pela definição, controle e avaliação das metas, sendo que algumas instâncias têm mais poder, e, portanto, mais autonomia, tanto na formulação quanto na implementação e na avaliação das políticas. Então, com base em resultados, o planejamento é redefinido e são traçados os percursos de consecução de novas metas e definido o financiamento de ações subações.

O último indicador da área de avaliação da aprendizagem é "Política específica de correção de fluxo" que, no PAR de 2007, foi pontuado de forma satisfatória e não gerou nenhuma ação. $\bigcirc$ diagnóstico levado a efeito pela Secretaria Municipal de Educação evidencia essa política desenvolvida, parcialmente, com os alunos dos anos iniciais do Ensino Fundamental. Em 2011, no entanto, a situação se apresentava crítica, sendo necessário implementar uma política de correção de fluxo em toda a rede de ensino, tendo em vista a distorção idade série.

Por isso, foi gerada a ação "Definir e implementar políticas para a correção do fluxo escolar" (MOSSORÓ, 2011 1). No seu desdobramento, propuseram-se duas subações de assistência do município: proporcionar condições técnicas para qualificar professores e outros profissionais da escola em 
Políitica de avaliação da aprendizagem no planejamento educacional do Município de Mossoró/Rio Grande do Norte

atividades para prevenir a distorção idade-série, levando em conta as especificidades linguísticas e culturais de comunidades indígenas, quando existem. Também foi contemplada a elaboração do plano com o objetivo de regularizar - fluxo escolar na rede de ensino municipal, com prazos definidos, a partir da identificação dos alunos com aprendizagem defasada. Contou com a assistência técnica do MEC por meio do Programa de Correção de Fluxo Escolar com atividades pautadas no Guia de Tecnologias Educacionais, tendo por objetivo reverter a situação de fracasso escolar (MOSSORÓ, 2011).

Assim, entendemos que a proposta de correção de fluxo no PAR é uma expressão das políticas delineadas na "Declaração Mundial sobre Educação para Todos (1990) - Satisfação das Necessidades Básicas de Aprendizagem". Nelas, a aprendizagem constitui-se no argumento do sucesso a ser mantido e/ ou do fracasso escolar que deve ser superado. Essa perspectiva relaciona-se com a centralidade que é atribuída à educação básica como imperativo das forças mercadológicas que associam o baixo desenvolvimento econômico ao patente fracasso escolar. É, pois, compatível com a principal meta dessa declaração: promover a educação de todos os cidadãos do planeta.

Nesse princípio de universalização da educação e do ensino-apren-

116 dizagem, conflui a perspectiva de qualidade associada à produtividade, não, apenas, material, mas também relativa ao conhecimento, à construção de valores culturais e morais comuns. Consideramos importante formular e implementar programas que atendam às demandas formativas de estudantes com aprendizagem defasada, baseada na Lei de Diretrizes e Bases da Educação, Lei 9.394, de 20 de dezembro de 1996. $O$ art. 12, Inciso V, incumbe os estabelecimentos de ensino a promover os "[...] meios para a recuperação dos alunos de menor rendimento [...]" (BRASIL, 1996, p. 167). Ressalta, ainda, o dispositivo legal que os prejuízos causados à aprendizagem de crianças e jovens são incomensuráveis, inclusive contribuindo para que delas seja retirada a "[...] possibilidade de avanço nos cursos e nas séries mediante verificação do aprendizado [...]" (BRASIL, 1996, p. 170). Ademais, o atraso na escolaridade compromete a autoestima, a sociabilidade, retardando, também, a inserção dos jovens e adultos no mundo do trabalho.

Quanto ao argumento de melhorar o fluxo escolar, em atendimento a determinações legais, a União, por meio do PAR nos municípios, desenvolve ações específicas voltadas ao atendimento de alunos. Desenvolvendo determinadas atividades, supõem os propositores de políticas educacionais que 
Francisca Edilma Braga Soares Aureliano | Luciane Terra dos Santos Garcia | Maria Aparecida de Queiroz

correspondem a especificidades culturais e regionais inerentes ao problema da distorção idade série ou ano de escolaridade. Assim, nunca é demais insistir que a correção do fluxo escolar evidencia os propósitos políticos de universalização do Ensino Fundamental, de melhorar os índices educacionais transferindo, no entanto, responsabilidades da União para os Estados, municípios, Distrito Federal e instituições de ensino.

\section{Considerações finais}

A avaliação processual proposta no PAR decorre dos compromissos assumidos pelos países que subscreveram o pacto pela melhoria dos resultados da educação em Jomtien (1990). Focalizadas em ações que orientam as estratégias para a aprendizagem, as políticas induzem a que, nas escolas, as equipes pedagógicas e os professores assegurem assistência individual e coletiva aos alunos que enfrentam dificuldades em aprender. Assim, o fluxo escolar pode ser corrigido mantendo o equilíbrio entre a idade/série ou ano de escolaridade.

Esse é um dos principais objetivos do PAR enquanto contribuição ao desenvolvimento de aprendizagens, de habilidades, competências, atitudes e valores necessários à formação integral dos estudantes. As intenções e as práticas inerentes ao programa são conduzidas de modo a proporcionar melhoria nos resultados do ensino. Estes, supostamente, têm, como consequência direta, a melhoria da aprendizagem, repercutindo, portanto, nos índices educacionais.

Conforme essa lógica, a melhoria da aprendizagem implica a definição de indicadores e no desenvolvimento de ações e subações. Analisando o PAR de Mossoró/Rio Grande do Norte, constatamos sua correspondência com a meta do PDE direcionada à melhoria da qualidade da educação básica, em cumprimento aos acordos firmados entre o Brasil com os organismos multilaterais. Assim, o controle sobre a aprendizagem se torna nodal para avaliar o custo benefício relativo aos investimentos em educação. A Prova Brasil, como estratégia na composição do ldeb, é, portanto, a principal referência para aferir a qualidade da aprendizagem dos estudantes. Parâmetro para a prestação de contas dos investimentos em educação, principalmente, aqueles originados em acordos de empréstimo externos. 
Políitica de avaliação da aprendizagem no planejamento educacional do Município de Mossoró/Rio Grande do Norte

Essa política de avaliação e controle que envolve todos os estudantes independe de terem dificuldades em aprender ou necessidades educacionais especiais; de serem bem dotados e, supostamente, bem-sucedidos na escola e na vida. Na contabilidade, mantém-se a crença de que ações e subações de assistência aos estudantes levarão, nas avaliações oficiais, ao decréscimo do fracasso escolar.

Nesse sentido, na análise desses aspectos no PAR de Mossoró/RN (2007; 2011 ), percebemos que, por ocasião do primeiro, já se desenvolvia um trabalho efetivo da Secretaria Municipal de Educação para atendimento aos estudantes com dificuldades em aprender. Por isso, para o quadriênio seguinte, acrescentou, apenas uma subação que orientava as equipes ao uso de novas metodologias no trabalho pedagógico. Os demais critérios necessários à aprendizagem pareciam ser considerados a contento.

O segundo PAR (201 1), por sua vez, dispensou as subações de acompanhamento aos processos de aprendizagem. Aderiu, por sua vez, ao que prescreve a Lei Municipal n² 2.217 de 27 de dezembro de 2010 de responsabilidade educacional ao regulamentar a avaliação meritocrática. Esse princípio de gestão, aplicado à rede de ensino fundamental, induz à competição entre 118 sujeitos e instituições, pautando, dessa forma, a avaliação nesse sistema de ensino municipal. Consequentemente, a avaliação da aprendizagem perde o seu significado processual e formativo, traduzindo-se em práticas classificatórias e hierarquizantes que comprometem a inclusão dos excluídos.

Nesse sentido, a política de avaliação do município de Mossoró corrobora, inclusive, a filosofia do PAR como programa nacional, a despeito de suas ações serem conduzidas, supostamente, pela concepção de avaliação processual. Ao propor a assistência individual e coletiva aos estudantes com dificuldades de aprendizagem, subjaz o entendimento de reduzir as desigualdades educacionais. Mas, na realidade, prevalecem os propósitos de elevar os índices de qualidade do ensino para atender, principalmente, aos compromissos assumidos em âmbito das políticas internacionais de educação. Respondem, também, os gestores da educação, às críticas internas provenientes de segmentos da sociedade e da política contrários ao governo.

Políticas de educação semelhantes ao Plano de Ações Articuladas (PAR) suscitam questionamentos que não podem ser respondidos de imediato, senão experenciando-as, conhecendo-as em profundidade e refletindo à luz 
Francisca Edilma Braga Soares Aureliano | Luciane Terra dos Santos Garcia | Maria Aparecida de Queiroz

de uma perspectiva teórica e metodológica que avance na compreensão de sua dinâmica em realidades específicas. Mais complexo, ainda, é adentrar a dimensão da avaliação da aprendizagem enquanto estratégia de política educacional do Estado brasileiro referenciada pela nova gestão pública. Os resultados que emanam da escola, notadamente, do processo de ensino e aprendizagem controlado por avaliações externas a esse ambiente, ainda obscurecem a real situação da educação, do ensino e das aprendizagens possibilitada pela escolarização de crianças, jovens e adultos.

\section{Notas}

1 projeto é uma iniciativa da linha de pesquisa Política e Práxis da Educação do Centro de Educação da Universidade Federal do Rio Grande do Norte (UFRN).

2 A Equipe Técnica deve ser constituída nos municípios pelos seguintes segmentos: Dirigente Municipal de Educação; técnicos da Secretaria Municipal de Educação; representante dos diretores de escola; representante dos professores da zona urbana; representante dos professores da zona rural; representante dos coordenadores ou supervisores escolares; representante do quadro técnico-administrativo das escolas; representante dos Conselhos Escolares; representante do Conselho Municipal de Educação (BRASIL, 2011 ).

3 Ferramenta tecnológica na qual são produzidas e monitoradas todas as políticas educacionais para os Estados e municípios (simec. mec.gov.br).

4 Pacto Federativo, atualmente chamado de Federalismo Fiscal, está definido na Constituição da República Federativa do Brasil (artigos 145 a 162), nos quais, se definem as competências tributárias dos entes da Federação, bem como as responsabilidades pelos encargos ou serviços públicos expostos nos artigos 21 a 32. O Pacto envolve a partilha da receita dos tributos arrecadados pelos entes federados, sendo exemplos desses mecanismos os Fundos de Participação dos Estados e do Distrito Federal e dos Municípios e os Fundos Constitucionais de incentivo ao desenvolvimento regional (Fundos Constitucionais do Norte, Nordeste e Centro-Oeste).

$5 \bigcirc$ Saeb foi criado, em 1990, para medir a aprendizagem dos alunos das escolas públicas e privadas a cada 2 anos, objetivando controlar a qualidade da educação e gerar informações para o planejamento das políticas educacionais, avaliando, apenas, por mostra representativa. Para ampliar esse processo, em 2005, foi criada a Prova Brasil, que abrange todas as escolas brasileiras, apreendendo, assim, uma realidade mais ampla.

6 Ideb (BRASIL, 2008) foi criado em 2007, pelo Instituto Nacional de Estudos e Pesquisas Educacionais Anísio Teixeira - Inep. Combina os resultados do desempenho do Saeb e Prova Brasil com dados do fluxo educacional provenientes do censo escolar possibilitando a atribuição de um índice de zero a dez às escolas, às redes de ensino e à educação do país. A definição desse indicador nacional dequalidade da educação, a despeito das críticas suscitadas, pode ser considerado um mecanismo de monitoramento, controle e avaliação. 
Políitica de avaliação da aprendizagem no planejamento educacional do Município de Mossoró/Rio Grande do Norte

7 Esse período foi marcado pela ditadura civil-militar instaurada no país, no período de 1964 a 1985. Conforme Germano (2005), se caracterizou pela realização de acordos entre o Mec e a Agência dos Estados Unidos para o Desenvolvimento Internacional, conhecidos como acordos Mec-Usaid, que abrangeu todos os níveis da educação nacional. Sob o discurso de propiciar a modernização educacional do país, reformou o ensino tomando, como base, uma racionalidade economicista e privatizante.

8 De acordo com o Guia de Orientações para elaboração do PAR (BRASIL, 2011 ) apresenta quatro formas de execução das ações: assistência técnica do MEC; assistência financeira do MEC; executadas pelo município; e outras formas de apoio que envolve outros parceiros.

$9 \bigcirc$ artigo $1^{\circ}$ da Lei $n^{\circ} 2.717$, de 27 de dezembro de 2010 assim define o seu conteúdo: "[...] institui a política de Responsabilidade Educacional no Município de Mossoró, com o objetivo de promover a melhoria da qualidade do Sistema Municipal de Ensino, por meio da execução de ações planejadas, do estabelecimento de metas educacionais, do investimento crescente e sistemático de recursos financeiros e da avaliação de desempenho, tendo, como foco principal, o aluno e, como resultado dessa política, a melhoria dos indicadores educacionais e sociais." Essa lei é, pois, bem mais ampla do que o PAR porque regulamenta a vida da educação em todo o município tendo, pois, um relativo caráter de permanência, enquanto o PAR é um programa transitório, indutor de financiamento da educação municipal.

\section{Referências}

ABRÚCIO, Fernando Luís. Os avanços e os dilemas do modelo pós-burocrático: a reforma da administração pública à luz da experiência internacional recente. In: BRESSER-PEREIRA, Luiz Carlos; SPINK, Peter (Org.). Reforma do Estado e administração pública gerencial. 7. ed. Rio de Janeiro: Editora da FGV, 2005.

ANDERSON, Perry. O Brasil de Lula. Novos Estudos, São Paulo, n. 91, p. 23-52, nov. 2011.

ARREDONDO, Santiago Castillo; DIAGO, Jesús Cabrerizo. Avaliação educacional e promoção escolar. Tradução Sandra Martha Dolinsky. Curitiba: IBPEX; São Paulo: UNESP, 2009.

AZEVEDO, Janete M. Lins de. A educação como políitica pública. Campinas: Autores Associados, 2003.

AZEVEDO, Sérgio de. Políticas Públicas: discutindo modelos e alguns problemas de implementação. In: SANTOS JÚNIOR, Orlando Alves dos; CHRISTOVÃO, Ana Carolina; NOVAES, Patrícia Ramos (Org.). Políticas públicas e direito à cidade: programa Interdisciplinar de formação de agentes sociais e conselhos municipais. Rio de Janeiro: Letra Capital/ Observatório da Metrópoles/IPPUR/UFRJ, 2011 (Caderno Didático). Disponível em: <http://observatoriodasmetropoles.net/download/miolo_livro_curso_baixada.pdf>. Acesso em:2 dez. 2013. 
AZZI, Sandra. Avaliação e progressão continuada. In: AZZI, Sandra (Coord.). Avaliação do desempenho e progressão continuada: projeto de capacitação de dirigentes. Belo Horizonte: SMED, 2001.

BARROSO, João. O Estado, a educação e a regulação das políticas públicas. Educação \& Sociedade. Campinas, v. 26, n. 92, p. 725-751, out. 2005.

BRASIL. Decreto Presidencial nº 6.094, de 24 de abril de 2007. Dispõem da implementação do Plano de Metas Compromisso Todos pela Educação. Diário Oficial [da] República Federativa do Brasil, Poder Executivo, Brasília, DF, 25 abr. 2007. p. 5.

BRASIL.Lei n 10.172, de 9 de janeiro de 2001 . Aprova o Plano Nacional de Educação e dá outras providências. Diário Oficial [da] República Federativa do Brasil, Poder Executivo, Brasília, DF, 10 jan. 2001, p. 1.

BRASIL. Lei n ${ }^{\circ} 11.653$, de 7 de abril de 2008. Dispõe sobre o Plano Plurianual para o período 2008/201 1. Diário Oficial [da] República Federativa do Brasil, Poder Executivo, Brasília, DF, 8 abr. 2008, p. 5.

BRASIL. Lei n 13.005, de 25 de junho de 2014. Aprova o Plano Nacional de Educação - PNE e dá outras providências. Diário Oficial [da] República Federativa do Brasil, Poder Executivo, Brasília, DF, 26 jun. 2014, p. 1. (Edição extra).

BRASIL. Lei $n^{\circ} 2717$, de 27 de dezembro de 2010. Institui a política de responsabilidade educacional no município de Mossoró e dá outras providências. Diário Oficial [da] República Federativa do Brasil, Poder Executivo, Brasília, DF, 28 dez. 2010, p. 1.

BRASIL. Lei n 9.394, de 20 de dezembro de1996. Estabelece as diretrizes e bases da educação nacional. Diário Oficial [da] República Federativa do Brasil, Poder Executivo, Brasília, DF, 23 dez. 1996, p. 27833.

BRASIL. Lei n 9.424, de 24 de dezembro de 1996. Dispõe sobre o Fundo de Manutenção e Desenvolvimento do Ensino Fundamental e de Valorização do Magistério, na forma prevista no art. 60, $\S 7^{\circ}$, do Ato das Disposições Constitucionais Transitórias, e dá outras providências. Diário Oficial [da] República Federativa do Brasil, Poder Executivo, Brasília, DF, 26 dez. 1996, p. 28442.

BRASIL. Ministério da Educação. O Plano de Desenvolvimento da Educação: razões, princípios e programas. Brasília: MEC, 2007.

BRASIL. Ministério do Planejamento. Plano Plurianual: desenvolvimento com inclusão social e educação de qualidade. Brasília: Ministério do Planejamento, 2008. (v. 1). 
Políitica de avaliação da aprendizagem no planejamento educacional do Município de Mossoró/Rio Grande do Norte

BRASIL. Orientações para elaboração dos Planos de Ação Articuladas (PAR) dos Municípios. Brasilia: MEC, 2007a.

BRASIL. Orientações para elaboração dos Planos de Ação Articuladas (PAR) dos Municípios Brasília: MEC, 2011.

CAMINI, Lucia. A política educacional do PDE e do Plano de Metas Compromisso Todos pela Educação. Revista brasileira de política e Administraçãa da Educação, Recife, v. 26, n.3, p. 535-550, set./dez. 2010.

CASASSUS, Juan. Descentralización de la gestión a las escuelas y calidad de la educación: mitos o realidades? In: COSTA, Vera Lúcia Cabral (Org.). Descentralização da educação: novas formas de coordenação e financiamento. São Paulo: Cortez, 1999.

CHUEIRI, Mary Stela Ferreira. Concepções sobre a avaliação escolar. Estudos em avaliação escolar, v. 19, n. 39, p. 49-64, jan./abr. 2008.

COHEN, Ernesto; FRANCO, Rolando. Avaliação de projetos sociais. RJ: Vozes, 1999.

COHEN, Ernesto; FRANCO, Rolando. Federalismo e relações intergovernamentais: implicações para a reforma da educação no Brasil. Educão \& Sociedade, Campinas, v. 31 , n. 112 , p. 729-748, jul.-set. 2010.

DIAS SOBRINHO, José. Avaliação: políticas educacionais e reformas da educação superior. São Paulo: Cortez, 2013.

ESTEBAN, Maria Teresa. A avaliação no processo ensino/aprendizagem: os desafios postos pelas múltiplas faces de cotidiano. Revista Brasileira de Educação. n. 19, p. 129-138, jan./abr., 2002.

FORMOSINHO, João; FERNANDES, António Sousa; MACHADO, Joaquim. Contratos de autonomia para o desenvolvimento das escolas portuguesas. In: FORMOSINHO, João; FERNANDES, António Sousa; MACHADO, Joaquim; FERREIRA, Henrique. Autonomia da escola pública em Portugal. Porto: Fundação Manuel Leão, 2010.

FREITAS, Luiz Carlos de. Os reformadores empresariais da educação: da desmoralização do magistério à destruição do sistema público de educação. Educação \& Sociedade, Campinas, v. 33, n. 119, p. 379-404, abr./jun. 2012.

GERMANO, José Willington. Estado militar e educação no Brasil. 4. ed. São Paulo: Cortez, 2005.

LUCKESI, Cipriano Carlos. Avaliação da aprendizagem escolar: estudos e proposições. 15. ed. São Paulo: Cortez, 2003. 
LÜDKE, Menga; ANDRÉ, Marli. Apesquisa em educação: abordagens qualitativas. São Paulo: EPU, 1986.

MOSSORÓ/RN. Prefeitura Municipal. Plano de Metas Compromisso Todos pela Educação: Plano de Ações Articuladas - PAR. Mossoró/RN, abril de 2007.

MOSSORÓ/RN. Prefeitura Municipal. Plano de Metas Compromisso Todos pela

Educação: Plano de Ações Articuladas-PAR. Mossoró/RN, abril de 2011.

Prefeitura Municipal. Lei $\mathbf{n}^{\circ} \mathbf{2} . \mathbf{7 1 7}$ de $\mathbf{2 7}$ de dezembro de $\mathbf{2 0 1 0}$ - Institui a política de responsabilidade educacional no município e dá outras providências. Mossoró/RN: Mossoró/RN: Palácio da Resistência, 2010.

ROMÃO, José Eustáquio. Avaliação dialógica: desafios e perspectivas. 9. ed. São Paulo: Cortez, 2011.

RUA, Maria das Graças. Análise de políticas públicas: conceitos básicos. In: RUA, Maria das Graças; CARVALHO, Maria Izabel V. (Org.). O estudo da política: tópicos selecionados. Brasília: Paralelo 15, 1998.

SAUL, Ana Maria Avela. A avaliação educacional. Disponível em: <http://www.ia.ufrri. br/ppgea/conteudo/conteudo-2009-2/Educacao-MII/2SF/Nadia/5-Aval_Educ_ideias. pdf>. Acesso em: 28 ago. 2014.

SECCHI, Leonardo. Políticas públicas: conceitos, esquemas de análise, casos práticos. São Paulo: Cengage Learning, 2010.

SOUZA, Celina. Políticas públicas: questões temáticas e de pesquisa.Caderno $\mathrm{CRH}$, Salvador, v. 16, n. 39, p. 11 -24, 2003.

Francisca Edilma Braga Soares Aureliano

Universidade do Estado do Rio Grande do Norte Doutoranda do Programa de Programa de Pós-Graduação em Educação Universidade Federal do Rio Grande do Norte Grupo de Pesquisa | Políticas e Gestão da Educação Bolsista do Conselho Nacional de Desenvolvimento Científico e Tecnológico | CNPq Pesquisadora do Observatório da Educação E-mail |edilmaaureliano@hotmail.com 
Profa. Dra. Luciane Terra dos Santos Garcia Universidade Federal do Rio Grande do Norte Centro de Educação Programa de Programa de Pós-Graduação em Educação Grupo de Pesquisa | Políticas e Gestão da Educação Pesquisadora do Observatório da Educação E-mail | Itsgarcia@gmail.com

Profa. Dra. Maria Aparecida de Queiroz Universidade Federal do Rio Grande do Norte Centro de Educação Programa de Programa de Pós-Graduação em Educação Grupo de Pesquisa | Políticas e Gestão da Educação Pesquisadora do Observatório da Educação E-mail | cidinhaufrn@gmail.com

Recebido 10 nov. 2014 Aceito 13 fev. 2015 